\title{
Fluoride concentration in drinking water in Shahroud (Northern Iran) and determination of DMF index in 7 year old children
}

\author{
Nazemi S, MSc ${ }^{1 *}$, Raei M, MSc ${ }^{2}$ \\ 1- Faculty member, Dept. of Environmental Health, School of Public Health, Shahroud University of Medical Sciences, \\ Shahroud, Iran. \\ 2- Faculty member, Dept. of Basic sciences, School of Medicine, Shahroud University of Medical Sciences, Shahroud, \\ Iran.
}

\begin{abstract}
:
Received: August 2011, Accepted: December 2011

Background: Fluorine is an essential micronutrient for human health, serving to strengthen the apatite matrix of skeletal tissues and teeth. In regions where the fluoride $(\mathrm{F}-$ ) concentration of water is naturally low $(<0.5 \mathrm{mg} / \mathrm{l})$, some communities have chosen to add this constituent to their drinking water to strengthen teeth and to minimize cavities. The aim of this study was to determine fluoride concentration in drinking water in shahroud city at the northern part of Iran as well as determination of DMF value in 7 year old children, for a duration of 6 years.

Materials and Methods: In this descriptive study, 138 students aged 7 were chosen randomly from Shahroud schools and were followed up for a duration of 6 years (2004-2009). They were examined by a dentist for determining the numbers of decayed, missing and filled permanent teeth. Also 120 samples were taken from drinking water in the city and Ion-selective method was used for measureing fluoride concentration. Determination of both DMF index and fluoride mean concentration was repeated for six years from 2004 to 2009.

Results: Fluoride concentrations were between 0.45 to $0.75 \mathrm{mg} / \mathrm{L}$ and DMF index was between 3.18 to 3.81 . There was a significant difference between both DMF index and fluoride mean concentrations in different years.

Conclusions: DMF index obtained in our study was higher than the index reported for the whole country $(1.2-2.6 \mathrm{mg} / \mathrm{L})$.
\end{abstract}

Key words : DMF, Drinking water, Fluoride concentration, School children.

\section{Introduction}

Flurine is found in the environment as fluorides, mainly because it is the most electronegative and reactive of all chemical elements. All natural waters have fluoride ranging from trace levels to several dozen $\mathrm{mg} / \mathrm{l} \cdot[1-2] \quad$ Fluorine is an essential micronutrient for human health, serving to strengthen the apatite matrix of skeletal tissues and teeth. In regions where the fluoride $(\mathrm{F}-)$ concentration of water is naturally low $(<0.5 \mathrm{mg} / \mathrm{l})$, some communities have chosen to add thisconstituent to their drinking water to strengthen teeth and to minimize cavities [1]. On the other hand, high $\mathrm{F}^{-}(>1.5 \mathrm{mg} / \mathrm{l})$ results in dental and skeletal fluorosis, renal and neuronal disorders and myopathy [3]. Endemic fluorosis develops widely in many areas of the world, such as China [4], India [5-7] and Mexico [8].

corresponding author: Saeid Nazemi, Dept. of Environmental Health, School of Public Health, Shahroud University of Medical Sciences, shahroud, Iran. E-mail:saied_nazemi@yahoo.com 
In Iran, the occurrence of high $\mathrm{F}^{-}$ groundwater has been reported in Dashtestan [9]. Exceptionally higher values were also found such as flouride concentration in the water of some lakes in Kenya where the content of fluoride is over $2000 \mathrm{mg} / \mathrm{l}$ [2]. It is generally accepted that fluoride is an essential component of all diets and that most of the body requirements are obtained from drinking water. A small fraction of this fluoride accumulates on the teeth and bones and most of it is eliminated in urine and sweat. An excessive concentration of fluoride can cause fluorosis [3]. Water fluoridation at the $1.0 \mathrm{mg} / \mathrm{L}$ level is supposed to be beneficial for caries prevention although excessive ingestion of fluoride during maturation could cause dental fluorosis.

There is a big controversy on the usefulness of fluoride in protecting tooth decay. In 1984 , world health organization recommended keeping the concentration of fluoride in range of $0.5-1.5 \mathrm{mg} / \mathrm{L}$ in order to prevent dental caries especially in children [13-14]. It is known that relative effectiveness of systematic fluoridation has diminished over time since the 1990s [10-15]. The aim of this study was to determine fluoride concentration in drinking water in Shahroud city (northern Iran) and also to determine DMF index between school age students in a duration of six years from 2004 to 2009.

\section{Materials and methods}

This cross sectional study was carried out in Shahrood city in Northern part of Iran on drinking water as well as measuring DMF among 7 year old school children (boys) from 2004 to 2009. A sample size of students was estimated as 138 subjects based on: prevalence $=20 \%, \alpha=0.05$ and precision $(d=0.07)$. The subjects were selected randomly from the list of all the 7 year old school children. A study questionnaire was completed. The data analysis was performed in SPSS (version 11.5) using one way ANOVA test.

120 samples were taken from the drinking water in Shahroud city and the level of fluoride concentration was determined for each year. Fluoride concentration was determined electrochemically, using approved USEPA ion-selective method (method 3402) [13] the electrode used was a fluoride/combination fluoride elector-orion 96-09 which was coupled to an Orion 420A electrometer $(\mathrm{pH}$ meter). Standards were prepared from a stock solution $(100 \mathrm{mg} / \mathrm{l})$ of sodium fluoride. This is applicable to the measurement of fluoride in drinking water, surface water and saline waters in a range of concentration from 0.1 up to $1000 \mathrm{mg} / \mathrm{l}$.

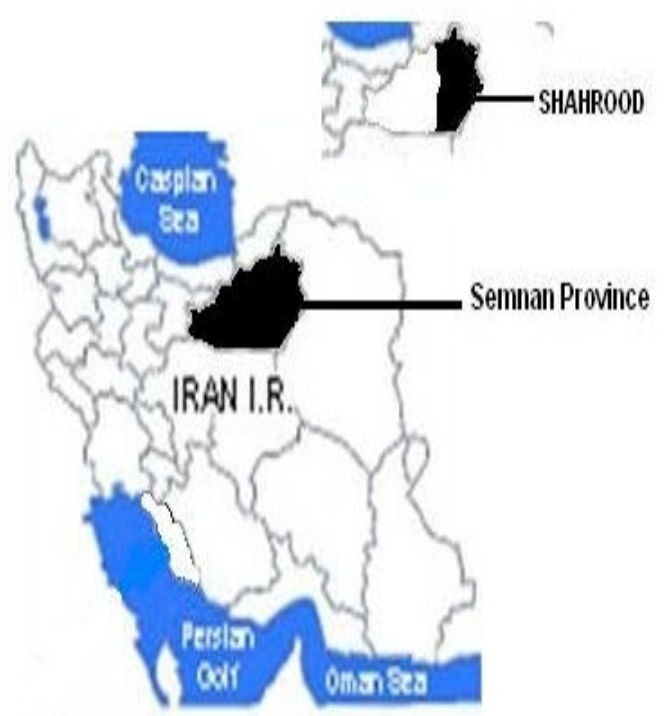

Figure 1. Location of Shahroud in Iran

Further, 138 students, aged 7 years old, were randomly chosen and examined by a dentist in schools for determining the numbers of decayed, missing and filled permanent teeth. Measuring both fluoride concentrations and DMF index were repeated for six years as the sample of students was followed up. In fact, the students were $8,9,10,11$ and 12 years old in years: 2004, 2005, 2006, 2007, 2008 and 2009 respectively. Locations of the samples where the water were taken during 
the study were not changed. Samples were collected in clean fluoride free plastic bottles directly from 120 sites. Trace grade nitric acid was added to preserve the samples. The samples were then stored at approximately 5 ${ }^{\mathrm{oc}}$ and the amount of fluoride was determined in the laboratory of school of health.

\section{Results}

The mean concentrations of fluoride in the water samples are shown in table 1 . As it is presented, the range of fluoride level during the six years of study was between 0.45 and $0.75 \mathrm{mg} / \mathrm{l}$. The lowest mean fluoride level was $0.45 \mathrm{mg} / \mathrm{l}$ for 2006 and the highest was $0.75 \mathrm{mg} / \mathrm{l}$ for 2009 . The mean fluoride levels were approximateiy the same for winter and summer in all of 120 locations that samples were collected. A one way ANOVA was conducted to compare fluoride level means in years :2004, 2005, 2006, 2007, 2008 and 2009. There was a significant effect for time, Wilks' Lambda $=0.05, \quad \mathrm{p}<0.001$. No fluoridation program has been set for this city up to day. The numbers of decayed, missed and filled tooth and mean values of DMF index and mean values of fluoride during the yesrs of study have been shown in table 1 .

Table 1. Mean values of DMF index and Mean values of Fluoride concentration

\begin{tabular}{ccccccc}
\hline Year & $\mathbf{N}$ & $\mathbf{D}$ & $\mathbf{M}$ & $\mathbf{F}$ & DMF index & $\begin{array}{c}\text { Fluoride Level(mg/l) } \\
\text { Mean } \pm \text { sd }\end{array}$ \\
\hline 2004 & 138 & 2.61 & 0.13 & 0.43 & 3.18 & $0.65 \pm 0.06$ \\
2005 & 138 & 2.69 & 0.17 & 0.43 & 3.30 & $0.55 \pm 0.06$ \\
2006 & 138 & 2.77 & 0.20 & 0.44 & 3.42 & $0.47 \pm 0.05$ \\
2007 & 138 & 2.60 & 0.29 & 0.45 & 3.62 & $0.65 \pm 0.06$ \\
2008 & 138 & 2.94 & 0.31 & 0.45 & 3.70 & $0.65 \pm 0.07$ \\
2009 & 138 & 3.01 & 0.34 & 0.45 & 3.81 & $0.75 \pm 0.04$ \\
\hline
\end{tabular}

Results showed that values of DMF index in our study were higher than the national average of DMF index. DMF index for Iran on the basis of world health organization reports is in range of 1.2 up to 2.4. Value of DMF index has incrased with the increase of the student's age and the increasing trend of decayed teeth is more than increasing trends of missing and filled teeth. The numbers of decayed, missed and filled teeth over the study duration are compared in Figure2.

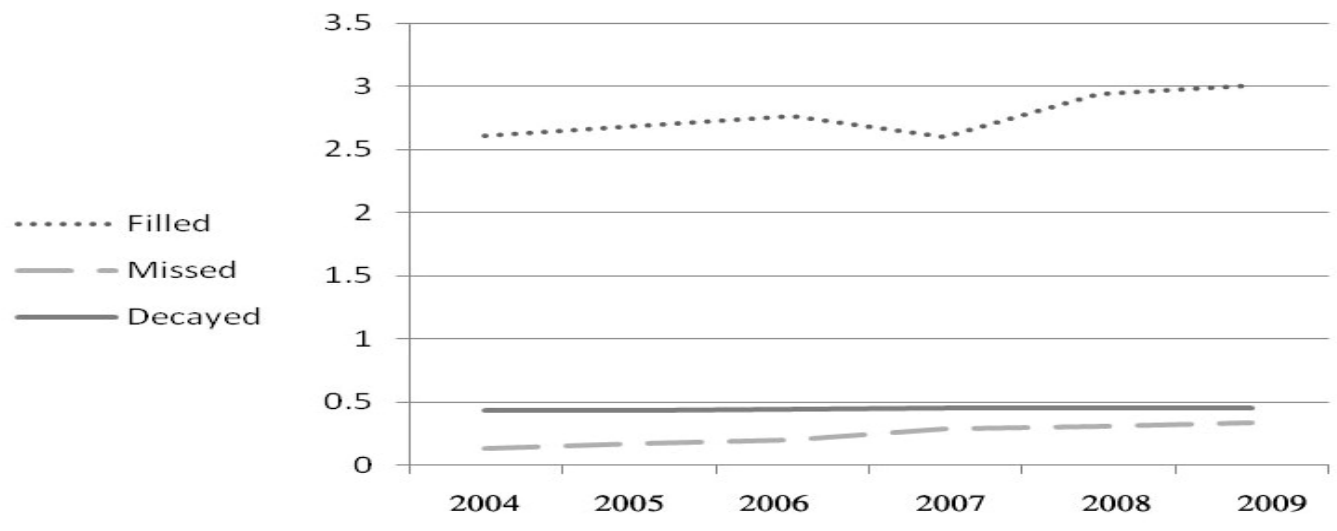

Figure2. means of decayed, missed and filled tooth among students 


\section{Discussion}

Previous studies show that the DMF prevalence among students of Baboul town was reported as $2.98 \pm 1.98$ in the 12-yearolds [16]. The DMF value was higher in girls than in boys. In another survey in Mashhad, the DMF was reported to be, $2.32 \pm 2.34$ in boys and $2.52 \pm 2.12$ in girls [10]. Majidi reported DMFT of 0.33 for boys 0.58 and for girls 0.087 [17]. The results of our study showed that as values of flouride increase, DMF index increases too, but this association is not significant. In places with low and optimal fluoride concentration in drinking water the percentage of children with decayed teeth was different, but this difference was not statistically significant. The percentage of affected deciduous teeth was high in all places. In places with low fluoride concentration this percentage was 4.2-12.7\%, and in places with optimal concentration was reported to be $4-12 \%$. The average value of DMF in all places is between 3.18-3.81. These results show that the optimal fluoride concentration in drinking water decreases the incidence of tooth decay, but this difference was not significant. Our results showed that values of DMF index were higher than the national average. DMF index for Iran on the basis of world health organization reports is in range of 1.2 up to 2.4 .

Studies done in three communities of Iran showed that DMF index was 4.4, 6.0 and 5.0 in students aged 9 years-old in Tehran(16), Semnan and Village of Dibaj, respectively [17]. These values are higher than DMf index values for Shahroud city.

A study in England [14] showed that DMF index was 2 in 2 -year-old children. Also, a study done in Broken bow [15], showed that DMF index was 3.6. The mean concentrations of fluoride in the water samples, during the six years of study was between 0.45 and $0.75 \mathrm{mg} / \mathrm{l}$ which is placed in low to middle level and, therefore flouride should be added to drinking water to increase fluoride concentration to a minimum of 1 $\mathrm{mg} / \mathrm{L}$ regarding the regional temperature (approximately $25^{\circ}$ ). A study in Spain [11] showed that fluoride concentration was between $0.001-1.9 \mathrm{mg} / \mathrm{l}$ in village of Almaluez. In another study [19] fluoride concentration in tap water in chile [19] was between $0.07-1.1 \mathrm{mg} / \mathrm{L}$. Another study in Broken bow [9] showed that fluoride level was low $(<0.3 \mathrm{ppm})$. All the results of these studies show that the natural amount of fluoride in drinking water are different all over the world.

\section{Conclusions}

Fluoride continues to be the cornerstone of dental caries prevention throughout the world, and there are a variety of sources of fluoride that may contribute to the dietary intake of fluoride. Eventhough Shahroud is considered as a non-endemic area for dental fluorosis according to its low concentration of fluoride in drinking water, the children in our study presented epidemiological indicators of overexposure to fluoride. pidemiological indexes showed simultaneously high prevalences of caries. Because our knowledge is incomplete regarding the amount, duration, and timing of fluoride ingestion which can result in dental fluorosis, further research is clearly needed before definitive recommendations can be made regarding the use of fluorides, including the recommended dietary intake of fluoride. Further longitudinal studies are also needed to determine the safe fluorine dose for Shahroud children, taking in account age, nutritional status, altitude, geographical location and weather among other factors. 


\section{Acknowledgement}

The authors would like to acknowledge the research financial supports of Dean of Shahroud University of Medical Sciences.

Conflict of interest: Non declared

\section{References}

1- Hurtado R, Gardea Torresdey J, Tiemann J. Fluoride occurrence in tap water at water at Los Altos De Jalisco in the central Mexico region. Presented at the 2000 conference on hazardous wastes research, Mexico, May 23-25, 2000.

2- Whelton H, Crowley E, O'Mullane D, Donaldson M, Kelleher V, Cronin M. Dental caries and enamel fluorosis among the fluoridated and non-fluoridated populations in the Republic of Ireland in 2002. Community Dent Health 2004; 21(1):37-44.

3- Sanz Perez E, Sanz J. Fluoride concentration in drinking water in the province of Soria (centeral Spain) and carries in children. Environ Geochem Health 1999; 21(2):13340.

4- Guo Q, Wang Y, Ma T, Ma R. Geochemical processes controlling the elevated fluoride concentration in groundwaters of the Taiyuan Basin, Northern China. Journal of Geochemical Exploration 2007; 93(1):1-12.

5- Subba Rao N, John Devadas D. Fluoride incidence in groundwater in an area of Peninsular India. Environ. Geol 2003; 45(2):243-251.

6- Gupta S, Deshpande R, Agarwal M, Raval B. Origin of high fluoride in groundwater in the North Gujarat-Cambay region, India. Hydrogeology Journal 2005; 13:596-605.

7- Jacks G, Bhattacharya P, Chaudhary V, Singh KP. Controls on the genesis of some high-fluoride groundwater in India. Appl Geochem 2005; 20(2):221-228.

8- Carrillo-Rivera JJ, Cardona A, Edmunds WM. Use of abstraction regime and knowledge of hydrogeological conditions to control high fluoride concentration in abstracted groundwater: San Luis Potosý basin, Mexico. Journal of Hydrology 2002; 261(1-4):24-47.
9- Dobaradaran S, Mahvi AH, Dehdashti S. drinking water fluoride and child dental caries in Dashtestan, Iran. Fluoride 2008; 40:93-94.

10- Meyer-Luwker H, paris S, Shirkhani B, Hopfenmuller W, Kielbassa AM. Carries and fluorosis in 6-and9-year-old children residing in three communities in Iran. Community Dent Oral Epidemiol 2006; 34(1):63-70.

11- Maupome G, Clarck DC, Lery SM, Berkowitz J. Patterns of dental carries following the cessation of water florideation. Community Dent Oral Epidemiol 2001; 29(1):37-47.

12- Seppa L, Karakkainen S, Hausen H. Carries trends 1992-1998 in two low-fluoride Finnish towns formerly with and without fluoridation. Caries Res 2000; 34(6):462-8.

13- Rum G, Lee WY, Gardea-Torresdey J. Application of an USEPA approved method for fluoride determination in an environmental chemistry laboratory: Fluoride detection in drinking water. J Chem Educ 2000; 77:1604-1607.

14- Riley JC, Lwnnon MA, Ellwood RP. The effect of water fluoridation and social inequalities on dental carries in 5-year-old children. Int J Epidemiol 1999; 28(2):300-5.

15- Wondwossen F, Ástrøm AN, Bjorvatn K, Bårdsen $\mathrm{A}$. The relationship between dental caries and dental fluorosis in areas with moderate-and high-fluoride drinking water in Ethiopia. Community Dent oral Epidemiol 2004; 32(5):337-44.

16- Mahyaee P. DMFT prevalence and caries free study on the 12 year old students in Baboul town in the year 2000. Tehran: University of Islamic Azad, Dental faculty; 2000.

17- Majidi E. Dental fluorosis rate determination and its relation to DMFT in Dayer town (Bushehr province) 1994-1995. Tehran: Tehran University of Medical Sciences, Hygiene faculty; 1995.

18- Mahvi AH, Zazoli MA, Younecian M, Nicpour B, Babapour A. Survey of fluoride concentration in drinking water sources and prevalence of DMFT in the 12 years old students in Behshahr city. J Med Sci 2006; 6(4):658-661.

19- World Health Organization (1997). Oral health survey. Basic methods. $4^{\text {th }}$ ed. Geneva: WHO. P11-3.

20- Nouri J, Mahvi AH, Babaei A, Ahmadpour E. Regional pattern distribution of groundwater fluoride in the Shush aquifer of 
Khuzestan County, Iran. Fluoride 2006; 39(4): 321-5.

21- Villa AE, Guerrero S, Villalobos J.

Estimation of optimal concentration of fluoride in drinking water under conditions prevailing in Chile. Community Dent Oral Epidemiol 1998; 26(4):249-55 